\title{
Emission budget approaches for burden sharing: some thoughts from an environmental economics point of view
}

\author{
Markus Ohndorf $^{1} \cdot$ Julia Blasch $^{2} \cdot$ Renate Schubert $^{1}$
}

Received: 26 February 2015 / Accepted: 27 May 2015 / Published online: 24 June 2015

(C) Springer Science+Business Media Dordrecht 2015

\begin{abstract}
In this paper, we examine budget approaches as a device for burden sharing in mitigating climate change. The purpose of this comment is twofold: First, we provide an overview over the general concept of budget approaches and investigate into the role of such approaches within the current climate negotiations. Second, as these approaches have an obvious normative dimension, we discuss some of the issues raised by Schuppert and Seidel (2015) in this Special Issue from the stance of an environmental economist. We highlight that budget approaches may serve as a tool to communicate the urgency of action against climate change and to remind representatives from industrialized countries of their responsibility in the historical sense as well as in terms of ability-to-pay. This even holds when the allocation of national emission shares is based on relatively easy-to-calculate sharing rules that can potentially serve as normative heuristics.
\end{abstract}

\section{Introduction}

From the perspective of environmental economists, climate change is currently the largest global environmental externality. An externality, in turn, is a common phenomenon in human interaction, where agents do not take into account the cost inflicted by their actions on third parties. In the case of global climate change, the externality consists in greenhouse gas emissions caused by different individuals or countries with the amount of emissions varying strongly between single emitters. Furthermore, there is a large variation between countries with respect to the damages from climate change suffered. It is this distinctness in polluter and pollutee which

This article is part of a Special Issue on "Climate Justice in Interdisciplinary Research" edited by Christian Huggel, Markus Ohndorf, Dominic Roser, and Ivo Wallimann-Helmer.

This paper is linked to the following contribution of this special issue: Schuppert and Seidel, doi:10.1007/ s10584-015-1409-z

Markus Ohndorf

ohndorf@econ.gess.ethz.ch

1 Chair of Economics, ETH Zurich, Clausiusstrasse 37, 8092 Zurich, Switzerland

2 Chair of Energy and Public Economics, ETH Zurich, Zürichbergstrasse 18, 8032 Zürich, Switzerland 
lies at the heart of climate change being both an ethical problem and a political conundrum. Within this conflicting duality between the normatively preferable and the politically feasible, one aspect is of particular importance: the sharing of the burden of mitigation among countries.

Burden sharing in mitigation (i.e., in the cost of emission reductions) is surely one of the most important justice-related issues in international climate policy, and represents undeniably the most important problem to be solved for a successful future climate agreement. ${ }^{1}$ From an economist's point of view, the underlying problem is clearly distributive in nature. Indeed, while economic efficiency, as well as moral intuition, call for taking (early) action against climate change, it is to keep in mind that this action comes with a cost, be it the form of reduced consumption of $\mathrm{CO}_{2}$-intensive goods or investments in low-carbon production processes. For example, according to IPCC (2014), keeping atmospheric greenhouse gases below 450 ppmv will entail cost corresponding to about one to four percentage points in GDP worldwide until 2030. In principle, these costs can be shared in various different ways, but surely some apportionments are considered to be more just and/or politically acceptable than others. Countries, their politicians, and their voters are likely to refuse mitigation actions if their cost are considered "too high", which also poses the question of a frame of reference for inter-country comparisons.

In order to provide such a frame of reference and to approach the problem of burden sharing more systematically, budget approaches have become more and more popular recently. Within these approaches, an overall target in cumulative emissions, that limits the increase in global mean temperature with a certain probability, is agreed upon. This global 'carbon budget' is then divided among polluters by allocating a certain amount of emission allowances to each individual country. A single country's emissions share defines thus the national carbon budget, i.e., the maximum amount of GHGs this country may emit within a given time frame. The allocation of emissions is derived from different (mostly ethical) principles (e.g., Grasso 2012; WBGU 2009). ${ }^{2}$ In their contribution to this Special Issue, Schuppert and Seidel (2015) use the budget approach proposed by the German Advisory Council on Global Change (WBGU 2009) to raise some important ethical concerns that are partly related to the choice of the underlying principle of distribution, while others are likely to arise within any type of budget approach.

In this comment, we pursue two objectives. First, given the importance of burden sharing in mitigation for the debate on climate justice, we consider it useful to discuss the merits of budget approaches in general to highlight the problems underlying the burden sharing debate and discuss the role of these approaches in the current negotiations. This first objective is addressed in sections 2 and 3. Second, in the spirit of the tandem structure of this special issue, we provide in section 4 a few thoughts from an economist's perspective on normative issues raised by Schuppert and Seidel (2015) with respect to the WBGU's Budget Approach, which also lends itself to discuss problems of budget approaches in general. Section 5 concludes.

\section{Burden sharing in mitigation}

Within the two decades of negotiations within the UNFCCC, countries with lower per capita GDP have mainly pointed to two normative principles to justify their exemption with respect

\footnotetext{
${ }^{1}$ As justice considerations within the field of adaptation to climate are covered in other contributions to this Special Issue, the following exclusively focuses on aspects of mitigation.

2 See Fleurbaey et al. (2014) for an overview.
} 
to binding emission reduction targets. The first is historical responsibility, stating that those countries that have contributed the most to atmospheric concentrations in the past are the ones that are morally obliged to take action first. The second principle is based on the ability-to-pay and states that countries with higher levels of GDP have larger resources to cope with the cost of mitigation. Note that this principle is not only an ethical one, but can also be based on economic efficiency. Given that utility is generally concave in consumption, countries with higher consumption levels lose less in aggregated social welfare than poorer countries when using part of their resources for emission abatement. Intuitively, this phenomenon can be exemplified by the fact that one dollar of consumption is worth more to a beggar than to a millionaire.

Even to non-ethicists, both of the above-mentioned distributive principles are morally intuitive and were taken into account when the UNFCCC was drafted in 1992. Indeed, one of the guiding principles of the Convention is the notion of 'common but differentiated responsibilities and respective capabilities', taking into account differences in national income when it comes to countries' action against climate change. Yet, as laid out in Michaelowa and Michaelowa (submitted for this issue) in this issue, the operationalization of this principle within a future international treaty has to change if the coalition is to encompass further large emitters. ${ }^{3}$ Since its entry into force in 2008 , the Kyoto Protocol indiscriminately exempts all of its parties from mandatory reduction targets that were considered developing countries in the 1990s (UNFCCC 1998). Yet, the recent advancements of the negotiations were only possible because emerging economies have signaled to take on mandatory reduction commitments in one form or the other in the future. While the underlying justice considerations continue to hold, the operationalization of the principle of common but differentiated responsibilities is likely to change. The range of proposals on how to share the burden of climate change mitigation in a more sophisticated manner is vast. Yet, up to the present, none of these proposals have been taken up within the drafts being negotiated within the UNFCCC.

\section{The global emissions budget in the current round of negotiations}

An important shortcoming of both Commitment Periods of the Kyoto Protocol was that the reduction targets were not based on insights from climate sciences but simply negotiated within the political bargaining process. While it is surely a first step to take on reduction targets in the first place, the current targets are not stringent enough to significantly reduce the risk of dangerous climate change, in particular as countries without commitments tend to offset the reduction efforts of the current coalition. A future agreement would hence have to a) be strict enough to considerably mitigate climate change, and b) distribute the burden of GHG abatement in a way that is perceived as "fair" and, most importantly, acceptable to all players.

In order to determine what might be a sufficiently strict agreement, emissions need somehow to be linked to the negative effects of climate change. Future damages from climatic change are dependent on changes in global mean temperature, which in turn depends on the concentration of GHGs in the atmosphere. In principle, it is possible to set a maximum level for each of these links in the causal chain, yet given the vast uncertainties associated with estimating future damages, it is more sensible to think in terms of concentration or global mean

\footnotetext{
${ }^{3}$ For the time being, the current round of the Kyoto Protocol represents a rather small coalition, including almost all European countries, Australia and Kasachstan (UNFCCC 2011).
} 
temperature. Naturally, a concentration target, like the $450 \mathrm{ppmv}$ target often referred to by the IPCC (e.g., IPCC 2014), represents in fact a target on cumulative emissions and is associated with relatively low levels of uncertainty. A temperature target, like the well-known $2{ }^{\circ} \mathrm{C}$ target, suffers from additional uncertainties associated with the radiative forcing of a concentration (IPCC 2014), but is easier to communicate as it helps to bear in mind which effects international climate policy is ultimately to prevent. Hence, while a temperature target is more difficult to translate into a value of admissible cumulative emissions, it has the advantage of being easy to communicate to politicians, their voters, and other influential stakeholders. The abovementioned $2{ }^{\circ} \mathrm{C}$ target was endorsed by the international community within the so-called Copenhagen Accord, as being the main objective of global mitigation efforts (UNFCCC 2010).

Note that translating such a temperature target into an amount of admissible emissions is necessarily probabilistic, as the sensitivity of the climate system with respect to concentration levels cannot be predicted with certainty. In an often-cited paper, Meinshausen et al. (2009) report the results of different attempts to calculate cumulative emission targets from the $2{ }^{\circ} \mathrm{C}$ guardrail. ${ }^{4}$ These and similar calculations inspired a type of burden sharing proposal, generally referred to as budget approaches. These approaches no longer focus on emission reduction pathways of single countries but are based on a global budget of admissible cumulative emissions over a specific time horizon. The budget is to be divided among countries according to one or more distributional principles (see e.g., Raupach et al. 2014 or Fleurbaey et al. 2014 for an overview).

In the realm of policy advice, several different budget approaches have been proposed, for example, by the expert group of the BASIC countries (BASIC 2011), as well as the German Advisory Council on Global Change (WBGU 2009). The latter attributes shares in emissions according to a country's population at a specific point in time (reference year), based on the idea of equal per-capita emissions. This approach is subject to the critical assessment in Schuppert and Seidel (2015) in this Special Issue.

The obvious advantage of budget approaches is that country targets, instead of being the subject of pure political bargaining as in the Kyoto Protocol, are ultimately based on scientific insights. Note, however, that this holds only for the sum of emissions, i.e., the global carbon budget, which is derived from an underlying temperature target. The allocation of the countries' emission shares, however, is strictly a distributive issue. This is where, depending on the viewpoint, the matter becomes either a question of justice considerations, or a subject of political bargaining.

As the general idea underlying budget approaches has some obvious appeal, it is now seriously considered within the current negotiations on future climate policy. In stark contrast to earlier attempts to a treaty, the draft document to be negotiated at the Conference of the Parties to the Convention in Paris by the end of 2015 includes several references to a budget approach. For example, the fourth option to be discussed as paragraph 5 of the treaty would comprise ${ }^{5}$.

\footnotetext{
$\overline{{ }^{4} \text { Note that even a warming of } 2{ }^{\circ} \mathrm{C}}$ cannot be regarded as "safe" (e.g., WBGU 2009), as even with temperature increases below that threshold, there exists a positive probability of catastrophic events. The $2{ }^{\circ} \mathrm{C}$ guard rail is hence rather a scientifically bolstered red line (e.g., Richardson et al. 2009; Allison et al. 2009; IPCC 2013), which was politically accepted by the international community, within the so-called Copenhagen Accord, as the main objective of global mitigation efforts (UNFCCC 2010). The German Advisory Council on Global Change, the proposal of which is controversially discussed in Schuppert and Seidel (2015), proposed already in the 1990s to limit global temperature increase to $2{ }^{\circ} \mathrm{C}$ (WBGU 1995) to reduce the risk of dangerous effects on the climate system, which would put significant stress on contemporary societies.

${ }^{5}$ A similar text is proposed for paragraphs $13.2 \mathrm{~b}$ ) and 16.1 .
} 
A global emission budget to be divided among all Parties, in accordance with the principles and provisions of the Convention, in order to limit global warming this century to below $1.5^{\circ} \mathrm{C}$ according to the Intergovernmental Panel on Climate Change (IPCC) assessment. The distribution of the global emission budget should be undertaken in accordance with historical responsibilities, ecological footprint, capabilities and state of development. (UNFCCC 2015, p.7).

Remarkably, this proposal features an even stricter temperature target of $1.5^{\circ} \mathrm{C}$. In order to achieve this level with a probability of $66 \%$ (50\%, respectively), IPCC (2014) reports cumulative $\mathrm{CO}_{2}$ emission from 2011 onward should not exceed $400 \mathrm{Gt}(550 \mathrm{Gt})$. Given that currently global $\mathrm{CO}_{2}$ emissions are about $40.3 \mathrm{Gt}$ per year (Friedlingstein et al. 2014), the $1.5^{\circ} \mathrm{C}$ target is undoubtedly very ambitious. At the current pace of emissions, the 400 (550) Gt mark will be exceeded within 6 (10) years. ${ }^{6}$

Furthermore, note that the proposal does not specify the exact principle on which shares should be calculated, but mentions a set of notions associated with different principles. Hence, there is currently no consensus on how a budget approach is to be integrated into an international treaty. It remains to be seen if and how much of the above-quoted proposal will be adopted in a binding manner. Some High-Level observers of the negotiations remain skeptical on budget approaches as a basis of negotiations, due to the restrictions they pose on potential political compromises (see, for example, Frame et al. 2014).

Yet, the merit of carbon budget considerations is that they demonstrate the urgency of necessary national action against climate change if the risk of more dangerous levels of temperature increase is to remain manageable (Baer et al. 2009; Frame et al. 2014). Focusing on cumulative emissions, i.e., a total global carbon budget, makes the gap between the countries' short-term proposals and the required long-term abatement efforts alarmingly obvious. The focus on a simple, easy-to-communicate approach reminding the urgency of concerted action is also apparent within WBGU (2009), discussed in this issue by Schuppert and Seidel. These authors raise several important ethical concerns, which partially apply to any type of budget approach that might be proposed. In the following, we take up some of these thoughts and provide some comments from an economist's perspective.

\section{Some thoughts on normative issues raised on the WBGU's budget approach}

The budget approach proposed by the WBGU was brought forward in the context of the runup to the international climate negotiations in Copenhagen. In this approach a carbon budget of $750 \mathrm{Gt}$ of cumulative fossil $\mathrm{CO}_{2}$ emissions between 2010 and 2050 is attributed to the world's countries based on the principle of equal per-capita emissions. The cumulative level of $750 \mathrm{Gt}$ is based on the calculations in Meinshausen et al. (2009), which presented the best estimate at the time of meeting the $2{ }^{\circ} \mathrm{C}$ with a probability of $66 \%$.

Table 1 summarizes the most important results for selected countries with respect to their emission allocation according to equal per-capita emissions, as featured in WBGU (2009). Despite the claim by Schuppert and Seidel that the "WBGU seems to allocate equal emission

\footnotetext{
${ }^{6}$ The remaining years are counted from 2015 onwards, with the emissions between 2011 and 2015 already being subtracted.
} 
rights for current people with too little regard for both, past injustices and overconsumption", Table 1 shows that the principle of equal per-capita emissions places a relatively heavy burden on industrialized countries and makes some of these countries "carbonbankrupt" after only a few years, whereas 'poorer' countries with low historical emissions continue to dispose of spare budget in the year 2050: Within WBGU (2009), almost all of the industrialized Annex-I countries, some Arab states, Venezuela, South Africa and Iran face significant budgetary shortfalls if they continue to emit $\mathrm{CO}_{2}$ as they did in 2008. Most emerging economies, like China, Mexico, Argentina, Chile and Thailand, would also start to experience such shortfalls but most likely after the year 2035. Only countries currently emitting less than $2.7 \mathrm{t} \mathrm{CO}_{2}$ per capita, like Afghanistan, Nepal, Egypt, Pakistan, Bangladesh or Peru, but also Brazil and India, would still experience a positive budget in 2050 if it is assumed that they continue with their 2008 per-capita emissions.

\subsection{On using equal per capita emissions as basis for emission allocations}

As correctly pointed out by Schuppert and Seidel, distributing emission shares which equalize per capita emissions seems to be, a priori, in violation with the justice concerns which are at the very heart of the burden sharing debate, in particular with notions of justice which support the principles of historical responsibility and ability-to-pay. They argue consistently that the same share in emissions does not necessarily reflect equality in the burden borne by each individual

Table 1 Coverage of the emission budget assuming annual emissions as in 2008

\begin{tabular}{|c|c|c|c|c|c|}
\hline & \multirow{2}{*}{$\begin{array}{l}\text { Share of world } \\
\text { population in } \\
2010[\%]\end{array}$} & \multicolumn{2}{|c|}{$\begin{array}{l}\text { Budget 2010- } \\
2050\left[\mathrm{Gt} \mathrm{CO}_{2}\right]\end{array}$} & \multirow{2}{*}{$\begin{array}{l}\text { Estimated } \\
\text { emissions in } 2008 \\
{\left[\mathrm{Gt} \mathrm{CO}_{2}\right]}\end{array}$} & \multirow{2}{*}{$\begin{array}{l}\text { Reach of the budget } \\
\text { lifetime, assuming annual } \\
\text { emissions as in } 2008 \\
\text { [years, starting from } 2010 \text { ] }\end{array}$} \\
\hline & & Total period & Per year & & \\
\hline Germany & 1.2 & 9.0 & 0.22 & 0.91 & 10 \\
\hline USA & 4.6 & 35 & 0.85 & 6.1 & 6 \\
\hline China & 20 & 148 & 3.6 & 6.2 & 24 \\
\hline Brazil & 2.8 & 21 & 0.52 & 0.46 & 46 \\
\hline Burkina Faso & 0.24 & 1.8 & 0.043 & 0.00062 & 2892 \\
\hline Japan & 1.8 & 14 & 0.34 & 1.3 & 11 \\
\hline Russia & 2.0 & 15 & 0.37 & 1.6 & 9 \\
\hline Mexico & 1.6 & 12 & 0.29 & 0.46 & 26 \\
\hline Indonesia & 3.4 & 25 & 0.62 & 0.38 & 67 \\
\hline India & 18 & 133 & 3.2 & 1.5 & 88 \\
\hline Maldives & 0.0058 & 0.043 & 0.0011 & 0.00071 & 61 \\
\hline EU & 7.2 & 54 & 1.3 & 4.5 & 12 \\
\hline World & 100 & 750 & 18 & 30 & 25 \\
\hline
\end{tabular}

Selection of countries as in WBGU (2009). (Source: WBGU 2009)

Option II: 'Future responsibility', 2010-2050; $67 \%$ probability of compliance with the $2{ }^{\circ} \mathrm{C}$ guard rail; 2010 as the reference year for population data. Only includes $\mathrm{CO}_{2}$ emissions from fossil sources; $\mathrm{CO}_{2}$ emissions for 2008 and population numbers for 2010 are estimations

Sources: WBGU, using data from: Meinshausen et al. 2009; WRI-CAIT 2009; US Census Bureau 2009 
country. An economist is tempted to agree. What determines the burden borne by a country is not the amount of emission reductions, but the cost to reduce these emissions. While the cost per tonne are limited by the fact that the WBGU approach allows for emissions trading, this does not guarantee an equal sharing of cost, neither in monetary, nor in utility terms. The latter might raise a problem not only as far as justice is concerned, but might also affect allocative efficiency, as the elasticity of utility of consumption is generally larger in poorer countries than in richer ones. Note that this holds generally for budget approaches which, using the terminology of IPCC (2014), should not be based on Resource sharing (i.e., rules based on emissions), but rather on Effort sharing, i.e., frameworks that seek a 'fair' distribution of cost.

Nevertheless, as it turns out, the use of a rule based on equal per-capita emissions within WBGU (2009) leads to an allocation which is quite restrictive as far as allocations to industrialized countries are concerned. Hence, even if "past injustices and overconsumption" are not directly addressed within this allocation rule, its potential distortions do not seem to favor such undesirable qualities. This is in line with the results in Grasso (2012) reporting a more restrictive allocation to industrialized countries for equal per-capita emissions than for operationalizations of both principles, historical responsibility and ability-to-pay. One could consider equal percapita emissions as a simple, easy to calculate shortcut to reliably place a higher burden on high income countries, corresponding, hence, to what one might call a normative heuristic.

\subsection{The $2{ }^{\circ} \mathrm{C}$ target as probabilistic constraint and political acceptability}

Schuppert and Seidel thoroughly and rightfully question the confidence level of $66 \%$ chosen for the $2{ }^{\circ} \mathrm{C}$ constraint. They argue that in other areas of public safety, admissible safety margins are significantly stricter. Indeed, it is not a priori reasonable to assume per se that this level of confidence is the one that is politically acceptable, in particular if one bears that even respecting the $2{ }^{\circ} \mathrm{C}$ guardrail does not reduce the probability of catastrophic events due to climate change to zero. Yet, what can be undoubtedly stated is that the constraint needs to be probabilistic. A fully consistent application of a maximin principle, as it might be derived via a radical interpretation of contractarian ethics, like Rawls (1971) or Gauthier (1986), would imply the immediate stoppage of all GHG emissions. ${ }^{7}$ In the worst case, this could lead to a situation reminiscent to pre-industrial times. It is, hence, quite safe to say that a deterministic temperature constraint is not politically acceptable.

Let us take this line of thought a bit further. Mathematically, a probabilistic constraint of $2{ }^{\circ} \mathrm{C}$ with a higher confidence level is quasi identical to a specific constraint with a stricter (expected) temperature target, but lower confidence. Yet, as our discussion of the $1.5^{\circ} \mathrm{C}$ target has shown, it is highly unlikely that this stricter target is going to be met in the timeframe left for reaction, provided the calculations of the IPCC are correct and emissions remain sufficiently close to the current levels. To put it bluntly, it is extremely unlikely (or near to impossible) that global emissions drop to zero within the next 6 years, as would be required for not violating the $1.5{ }^{\circ} \mathrm{C}$ constraint with $66 \%$ confidence. $^{8}$ If this target is still to be met we

\footnotetext{
${ }^{7}$ The maximin principle, derived in this strand of literature, prescribes chosing an action, for which those actors that are (expectedly) the worst off still fare better than they would with any other course of action.

${ }^{8}$ A similar arithmetic example can be made with respect to the $2{ }^{\circ} \mathrm{C}$ target and its associated confidence intervals. According to Friedlingstein et al. (2014), where slightly higher carbon budgets are assumed than by the IPCC, the requirement for meeting the $2{ }^{\circ} \mathrm{C}$ target at a confidence level of $66 \%$, corresponds to a global budget of $1000 \mathrm{Gt}$ in 2020. Hence, if the currently negotiated agreement is finally in place, emissions would have to be cut to zero after 20 years if we assume emissions to continue at the current pace.
} 
would have to ask the voters in each of world's countries to either agree to go back to preindustrial times within 6 years or face the huge cost of adjusting all production processes to zero emission levels at very short term. The same holds for a $2{ }^{\circ} \mathrm{C}$ target with sufficiently high confidence. For example, for a $2{ }^{\circ} \mathrm{C}$ target with a $75 \%$ confidence level, Held et al. (2009) report model calculations situating the necessary cost of abatement at 1.5 to $2 \%$ of global GDP in the timeframe 2020-2040.

Another useful way of making the associated abatement cost comprehensible is by calculating the level of carbon tax necessary to meet a probabilistic constraint. Quite optimistically, Richels et al. (2004) report a level of a global tax per tonne of $\mathrm{CO}_{2}$ for meeting the $2{ }^{\circ} \mathrm{C}$ target at $95 \%$ confidence within the range of 255 and 355 US-\$ in 2020 and between 409 and 637 US-\$ in $2030 .{ }^{9}$ It is questionable whether voters in all countries of the world are willing to bear these costs. We would hence argue that the political acceptability of the confidence interval of a probabilistic temperature constraint is not determined by the confidence level per se, but rather the cost associated with meeting the respective target.

Finally, Schuppert and Seidel bring forward the idea of political acceptability being probabilistic itself. Indeed, this notion is intuitive to anyone trying to predict the outcome of a particular vote or election. Schuppert and Seidel seem to infer that, policy advice should hence also include all suggestions which have only a marginal chance of being taken up in the negotiations. However, history has shown that the ratification of a treaty on climate policy is a vote taking place every 10 to 15 years, with a limited number of proposals being more extensively discussed. In this case, one might expect the designers of the treaty to be risk averse and focus, under the given time constraints, on those options with a larger probability of success. Surely, they would ultimately opt for a treaty that is more likely to be accepted by voters and parliaments in the different member countries. ${ }^{10}$

\subsection{Emissions trading as "Outsourcing justice"?}

WBGU (2009) also proposes the possibility of reallocating emission allowances via a trading of emission rights. Yet, using such emissions trading schemes as a climate policy instrument has recently been subject to criticism. For example, currently inter-firm exchange within the EU Emissions Trading System yields relatively low prices, casting doubt on the premise that such instruments are suitable to set effective incentives for low carbon investments. Note, however, that low prices are not the result of a malfunctioning of the market mechanism per se. The ETS suffers rather from an overallocation of emission rights to the industry, which can be partially ascribed to the exertion of political influence on the part of the big polluters (Koch et al. 2015). It is likely that alternative policy instruments, like emission taxes, would be just as susceptible to political lobbying, which would reduce their effectiveness in a similar manner (MacKenzie and Ohndorf 2012).

As the discussion on burden sharing deals with inter-country emissions trading, the underlying political problems differ from those arising with inter-industry trading. Schuppert and Seidel, for example, label the possibility of such intercountry trading, proposed by the WBGU, as "outsourcing justice" in order to "overcome the ethical shortcomings of the

\footnotetext{
${ }^{9}$ As a thought experiment, we leave it to the reader to calculate his/her associated yearly tax burden in dependence to his/her current carbon footprint.

${ }^{10}$ In this case proposition (V) in Schuppert and Seidel would have to be adjusted by a concave transformation of the value function, relaxing the constraint accordingly.
} 
exclusive focus on equality". Here, an environmental economist will more or less politely beg to differ. In fact, allowing for emissions trading is not outsourcing justice, but the mechanism to actually achieve it.

First of all and in stark contrast to non-tradable allowances, emissions trading leads to abatement at those locations where it is the most cost-effective. ${ }^{11}$ Countries with low-cost abatement potentials will reduce more emissions than prescribed by their allocation and sell this surplus to countries with high marginal abatement cost. Ideally, such cap-and-trade schemes lead globally to an equalization of marginal abatement costs, which is the necessary condition to minimize abatement cost within the whole system (i.e., globally in the case of the WBGU approach). Obviously, there is a moral obligation for cost effectiveness, as this allows higher levels of GHG abatement for any given level of funds. Hence, an institutional structure that is not cost effective will not exploit the full potential of abatement.

Second and more important to refute the idea of "outsourcing justice", any flexible quantity-based policy instrument (i.e., tradable emission allowances) is based on the idea of creating a scarcity value for emission reductions. This value does only exist via the fact that the demand side has a willingness to pay for emission rights, and suppliers have low enough abatement cost to be willing to sell allowances on the market. The difference between market price and the suppliers' abatement cost is what we call producers rent, or net gain. By seeking this rent, a country with a relative lax allowance will still engage in abatement up to the level where the cost of the last unit of abatement (or marginal abatement cost) is equal to the market price. Note that a laxer initial allowance allocation only has a higher value to a country as it yields a higher producers' rent, which is in turn only achievable with trading of emissions. Hence, if a country has been attributed a large amount of emission rights, it will be ceteris paribus better off, as is intended on the grounds of justice considerations. Note that this holds independent of the ethical principles which have led to a more generous allocation of emission rights in the first place. Now assume the absence of trading in emission allowances. In this case, countries which were attributed a larger amount of allowances than needed in the near future, will not be able to gain from this higher allowance, will not receive a producers rent, and will consequently have no incentive to engage in abatement activities. As there is no monetary rent to be gained from a larger allocation, there is also no "fair outcome" achieved in the sense of 'effort sharing' as defined in IPCC (2014). Again, this holds independent of the principle on which the initial allocation is based. Hence, tradability is not "outsourcing justice", but rather a necessary condition to realize equity when departing from country emission targets, independent on the actual equity principle on which the initial allocation is based. $^{12}$

\section{Conclusion}

While it remains to be seen to what extent budget approaches can play a role in a future international climate policy agreement, they seem to be an interesting tool to communicate the urgency of action. Breaking down the overall emission budget of admissible cumulative

\footnotetext{
${ }_{11}^{11}$ This holds at least under a large enough level of competition.

${ }^{12}$ It is sometimes argued that the possibility for industrialized countries to buy certificates elsewhere would lead to a lack of innovation in cleaner technologies in those countries. This does, however, not occur if the overall target is strict enough, which is certainly the case for the $2{ }^{\circ} \mathrm{C}$ target. In this case the anticipated market price is high enough to guarantee strong incentives for the development of low carbon technologies.
} 
emissions can be helpful to remind representatives from industrialized nations of their responsibility in the historical sense, as well as in terms of ability-to-pay, depending on the distributive principle applied. This function as a communication device can already be fulfilled with a relatively easy-to-calculate sharing rule based on equal per-capita emissions, although an operationalization of other definitions of equity would be preferable from an ethical stance. Closer considerations on the costs of staying below a specific (probabilistic) temperature constraint on which a budget is based again emphasize the need for bold and early mitigation action. Independent of the principle an emission budget is based on, emission allowances need to be made tradable in order to achieve both efficiency and the underlying goals with respect to fairness.

\section{References}

Allison I, Bindoff NL, Bindschadler PM, et al (2009) The Copenhagen diagnosis. Updating the world on the latest climate science. Climate Research Centre, University of New South Wales, Sydney

Baer P, Athanasiou T, Kartha S (2009) A 350 ppm emergency pathway, revised version November 23, 2009. EcoEquity, Stockholm Environment Institute (SEI)

BASIC Experts (2011) Equitable access to sustainable development: contribution to the body of scientific knowledge. BASIC Expert Group, Beijing

Fleurbaey M, Kartha S, Bolwig S, Chee YL, Chen Y, Corbera E, Lecocq F, Lutz W, Muylaert MS, Norgaard RB, Okereke C, Sagar AD (2014) Sustainable development and equity, in IPCC

Frame DJ, Macey AH, Allen MR (2014) Cumulative emissions and climate policy. Nat Geosci 7:692-693

Friedlingstein P, Andrew RM, Rogelj J, Peters GP, Canadell JG, Knutti R, Luderer G, Raupach MR, Schaeffer M, van Vuuren FP, Le Quéré C (2014) Persistent growth of CO2 emissions and implications for reaching climate targets. Nat Geosci 7:709-715

Gauthier D (1986) Morals by agreement oxford. Oxford University Press

Grasso M (2012) Sharing the emission budget. Polit Stud 60:668-686

IPCC (2013) Contribution of working group I to the fifth assessment report of the intergovernmental panel on Climate Change. In: Stocker TF, Qin D, Plattner G-K, Tignor M, Allen SK, Boschung J, Nauels A, Xia Y, Bex V, Midgley PM (eds) Climate Change 2013: The physical science basis. Cambridge University Press, Cambridge, United Kingdom and New York, NY, USA

IPCC (2014) Contribution of working group III to the fifth assessment report of the Intergovernmental Panel on Climate Change. In: Edenhofer O, Pichs-Madruga R, Sokona Y, Farahani E, Kadner S, Seyboth K, Adler A, Baum I, Brunner S, Eickemeier P, Kriemann B, Savolainen J, Schlömer S, von Stechow C, Zwickel T, Minx JC (eds) Climate change 2014: mitigation of climate change. Cambridge University Press, Cambridge, United Kingdom and New York, NY, USA

Held H, Kriegler E, Lessmann K, Edenhofer O (2009) Efficient climate policies under technology and climate uncertainty. Energy Economics, 31(1):50-61

Koch N, Grosjean G, Fuss S, Edenhofer O (2015) Politics matters: regulatory events as catalysts for price formation under cap-and-trade. Working Paper, available at SSRN: http://ssrn.com/abstract=2603115

MacKenzie IA, Ohndorf M (2012) Cap-and-trade, taxes, and distributional conflict. J Environ Econ Manag 63(1):51-65

Meinshausen M, Meinshausen N, Hare W, Raper SCB, Frieler K, Knutti R, Frame DJ, Allen MR (2009) Greenhouse gas emission targets for limiting global warming to $2{ }^{\circ} \mathrm{C}$. Nature $458: 1158-1162$

Michaelowa K, and Michaelowa (submitted for this issue) Rapid development and new responsibilities for climate change mitigation?, Climatic Change

Raupach MR et al (2014) Sharing a quota on cumulative carbon emissions. Nat Clim Chang 4:873-879

Rawls J (1971) A theory of justice. Belknap Press of Harvard University Press, Cambridge

Richardson K, Kammen DM, Steffen W, et al (2009) Climate congress synthesis report: climate change - global risks, challenges \& decisions. Copenhagen, 10-12 March. University of Copenhagen, Copenhagen

Richels RG, Manne AS, Wigley TML (2004) Moving beyond concentrations: the challenge of limiting temperature change, AEI-Brookings Joint Center for Regulatory Studies, 04-11

Schuppert, F and Seidel, C (2015), Equality, justice and feasibility: an ethical analysis of the WBGU's budget approach, Climatic Change. doi:10.1007/s10584-015-1409-z

UNFCCC - United Nations Framework Convention on Climate Change (1998) The Kyoto protocol, FCCC/CP/ 1997/7/Add.1, Dec. 10, 1997; 37 ILM 22. UNFCCC, Bonn 
UNFCCC - United Nations Framework Convention on Climate Change (2010) Copenhagen Accord. Report of the conference of the parties on its fifteenth session, held in Copenhagen from 7 to 19 December 2009, Addendum, Part two: action taken by the conference of the parties at its fifteenth session, $\mathrm{FCCC} / \mathrm{CP} / 2009$ / 11/Add1, 30 March 2010. UNFCCC, Bonn, Germany

UNFCCC - United Nations Framework Convention on Climate Change (2011) Decision 1/CMP.7, Outcome of the work of the Ad Hoc Working Group on further commitments for Annex I parties under the Kyoto protocol at its sixteenth session, FCCC/KP/CMP/2011/10/Add.1. UNFCCC, Bonn

UNFCCC - United Nations Framework Convention on Climate Change (2015) Work of the contact group on item 3, Negotiating text, Ad Hoc Working Group on The Durban platform for enhanced action, Second session, part eight, Geneva, Switzerland

US Census Bureau (2009) Unites States census 2010, United States department of commerce. http://www.census. gov. Accessed 24 June 2009

WBGU - German Advisory Council on Global Change (1995) Scenario for the derivation of Global CO2 reduction targets and implementation strategies. Statement on the occasion of the first conference of the parties to the framework convention on climate change in Berlin. Special report 1995. WBGU, Bremerhaven

WBGU - German Advisory Council on Global Change (2009) Solving the climate dilemma: the budget approach. Special report 2009. WBGU, Berlin

WRI-CAIT (2009) World resources institute - climate analysis indicators tools, version 6.0. http://cait.wri.org/. Accessed 3. June 2009 